\title{
TECHNOLOGICAL DEVELOPMENT IN SPANISH GOTHIC VAULTS DESIGN
}

\author{
José Carlos Palacios Gonzalo and Rafael Martín Talaverano \\ Escuela Técnica Superior de Arquitectura \\ Universidad Politécnica de Madrid
}

\begin{abstract}
The principle of complexity as the evolution vector of the gothic style was an idea largely developed by Paul Frankl. The high complexity reached in the $15^{\text {th }}$ and $16^{\text {th }}$ centuries was possible thanks to the geometrical resources developed in the workshops of the medieval stonemasons. The search for more sophisticated designs was possible also with the higher standardization, so that the most complex ribbed vault could be built with ribs that had all the same curvature and with voussoirs that were therefore identical. Spanish Gothic architecture has been deeply studied from a historical and artistic point of view. The present paper, as a complement to these analyses, aims to point out some of the geometrical methods and technological improvements that late medieval masons were able to develop. In that way, some selected vaults have been measured, in order to study their geometry and design process. Also scale models of some vaults have been built at the Escuela de Arquitectura (Madrid) to validate these geometrical principles. More than just a research method, the scale models allow to understand the medieval construction techniques, and they are a powerful pedagogical tool with which pupils can reach a rewarding experience based on the "medieval-way" praxis.
\end{abstract}

\section{1.- INTRODUCTION}

The Gothic was an architectural style which achieved to generate an aesthetic code. Since Elie Lambert's work (Lambert, 1920), Spanish Gothic style has been deeply studied from a historical and artistic point of view. The recent contribution by Javier Gómez Martinez provides a new point of view of the late Spanish Gothic architecture (Gómez, 1998). It is a well-known fact that this style represents the success of the ribbed vault which is, undoubtedly, one of the most revolutionary inventions in the history of construction. The present paper, as a complement to the historical and artistic analyses, aims to point out some of the geometrical methods and technological improvements that late medieval masons were able to develop.

The principle of complexity as the evolution vector of the gothic style was an idea largely developed in the middle of the last century by Paul Frankl. Some analyses (Bucher, 1972; Müller, 1990) have studied the geometrical methods of vault design, like "Prinzipalbogen", that made possible the construction of complex German late gothic vaults. This paper aims to complete Paul Frankl's idea by adding that the high complexity reached by the Spanish gothic technique was possible thanks to the geometrical resources developed in the workshops of the medieval stonemasons. It is about reaching as much complexity as possible but with the higher standardization, so that the most complex ribbed vault can be finally built with ribs that have all the same curvature and with voussoirs that are therefore identical. The advantages of this technique are obvious: all the voussoirs with which the ribs of the vault are built are equal and the wood centrings which will help its construction are identical. This paper presents the results of a geometrical analysis of several vaults, which have been measured. Moreover, after the analysis a scale model of some of the vaults has been 
built to validate the geometrical principles with the practical application, giving a new insight into this topic.

This activity is included in the research project "Stonecutting Technology in the Mediterranean and Atlantic Areas. Survey and analysis of built examples" (BIA200914350-C02-02), sponsored by the Ministry of Science and Innovation of the Spanish Government in the context of the National Plan for Research, Development and Innovation.

\section{2. - THE STANDARDIZATION OF THE VAULT}

\section{1. - Technological developments of Gothic design}

One of the distinctive features of Gothic architecture from its origin was the use of the pointed arch instead of the previously used semi-circular arch. The widespread use of this kind of arch, beyond constituting an essential stylistic feature, means an important technological evolution.

If the aim is to cover a certain span with a semi-circular arch, the solution is unique: the voussoirs will be determined by the radius of curvature of the circumference described by the arch. If, in the same work, another rib with a different span is required, the voussoirs needed would have a different radius of curvature; since the pieces are not interchangeable, each one requires its appropriate position.

On the other hand, when covering the same span with a pointed arch, the solution is indeterminate, that is, there are infinite pointed arches that could cover a certain span. Then, it is necessary to define another parameter which determines the solution to use. The most usual parameter used in medieval times was the height of its keystone, which determines the radius and the centre of curvature (assuming that this centre is on the impost line). The degree of indetermination inherent to geometry of the pointed arch is one of its most powerful advantages: when another arch covering a different span has to be built, it is possible to use the same radius of curvature, changing the height of the keystone. That allows the use of the same voussoirs for different ribs. Figure 1A shows a drawing by Viollet-le-Duc in which this principle is summarized. Through the application of this method to a star-shape ribbed vault (figure 1B), all ribs could be built with the same curvature as the diagonal rib.

Consequently, when using pointed arches, the organization, storage and assembling of the voussoirs is quite simplified in comparison with the use of semi-circular arches, especially when several adjacent vaults with slightly different measurements have to be built. Therefore, the use of the pointed arch entails a remarkable advantage for the organization of the works and the transmission of orders among the different members of the workshop constructing the building.

The evolution of the Spanish Gothic architecture in its latest period, during the transition from the late Middle Ages into the Modern Era, is marked by the development of more complex ribbed vaults, in which the ribs and the bosses which constituted them keep multiplying incessantly. The most usual model is the stellar groin vault, formed by five bosses (a central boss and four secondary bosses). This composition works as the basis for a great number of more complex vaults. As a general rule, all these vaults use arches with an unique centre located in the impost line of the vault (Rabasa, 2000). However, also vaults drawn with arches having three centres, i.e. ovals, are quite frequent (Willis, 1910). 


\section{2.- Methodological considerations}

When developing the present study, through the measurement and analysis of several late gothic Spanish vaults, it has been possible to establish some geometrical methods in order to design the vaults with the minimum number of different ribs' curvatures. Taking into consideration that historical masonry structures are almost always distorted (especially ribs and vaults), it was quite important to have a good reference of the current distorted geometry. That is why a systematic laser measurement of the vaults was previously made. For this purpose, two methods have been used. When measuring vaults with single-curvature ribs, the height of five points that belong to each rib has been obtained with a laser distance meter (typ. accuracy of $1 \mathrm{~mm}$ ); also the horizontal distance to a fixed reference point on the ground basis of the pile from where the rib starts has been measured. Finally, the height of the plane from where the rib starts has been obtained. Since the arches belong to a vertical plane, the measured points can be located on their corresponding three-dimensional situation. When measuring vaults with double-curvature ribs, a laser total station has been used to measure all the joints between the voussoirs of the ribs. This device allows to know the spatial location through a laser measurement (typ. accuracy of $1 \mathrm{~mm}$ ) and a common reference for all the points. The result has been imported into CAD, where the points have been obtained with their $\mathrm{X}, \mathrm{Y}, \mathrm{Z}$ coordinates.

After measuring several points from each rib, the corresponding line has been drawn between them. The first result is a plane line compound with several straight segments that are not an arch. That is why an interpretation has been made to set which circumference could better fit through these points. It is impossible to fit a circle that passes through all the points exactly, and some attempts have been made to find the best-fitted circle. When the rib has two curvatures, a double interpretation was made in order to know the best-fitted oval and the point where both curves joint. The results presented in this paper have an approximate accuracy of $2 \mathrm{~cm}$ (the maximum distance from any point to the best-fitted circle line). An acceptable geometrical analysis has been possible because of the inexistence of serious distortions in the vaults' ribs.

Once that the ribs have been geometrically analyzed, four methods to minimize the number of different curvatures for the ribs have been found, which are shown (in an approximately way) through sketches in figure 2 , and could be described as follows:

A. - The ribs have all the same curvature, using the radius of the diagonal rib. The heights of the bosses are a result of the geometry; they are not fixed previously.

B. - The ribs have all the same curvature, but the height of secondary bosses is fixed previously. The ribs have to be adjusted as necessary through a rotation of the arch around the starting point, moving their centres of curvature (which are not on the impost line).

C. - The ribs have all two radius of curvature (which are equal for all ribs). The diagonal rib is an oval, while other ribs are tudor arches. The height of the bosses is previously fixed, and the adjustment is obtained through the movement of tangency point (sliding the upper arch across the lower arch)

D. - The ribs have all two radius of curvature (which are equal for all ribs). The height of the bosses is also previously fixed, and all the ribs have the transition point between lower and upper segments of the arch at the same level. The necessary adjustments are made by rotating the upper segment of the rib around this transition point, moving its centre of curvature; generally, this point is not a tangency point between the two segments. 


\section{3. - Vaults in which all the arches have the same curvature}

When the vault's ground plan is a square, and the diagonal arches are semi-circular, it is possible to build wall-ribs and formerets with the same radius of these diagonal arches. In these cases, the boss stones of wall-ribs and formerets reach a slightly lower height than the central keystone. The result is a vault in which the ridge rib is almost horizontal. Besides, if the tiercerons have also the same radius, then the whole vault could be built with only one arch (figure 1). That allows making easier the carving of voussoirs and the construction of wood centrings.

This principle is applied in the vault that covers the transept in Astorga cathedral (figure 3). This vault, attributed to Rodrigo Gil, must have been built between 1550 and 1570. Its plan is square with a side $7.58 \mathrm{~m}$ long and its central keystone is $5.14 \mathrm{~m}$ high over the impost plan. It has a couple of tiercerons in each direction and also four liernes. The subsidiary ribs describe two figures tangent to each other: four lobes formed by segments of circumferences in the centre and a convex quadrilobe, ending in ogees. This design might be considered typical of the Hontañón family and, with some variations, repeated in many Castilian churches.

As shown in figure 4A, the tiercerons are located in the bisector of the angle formed by the diagonal and the formeret, the rest of the bosses come from the superposition of a $4 \times 4$ net over the plan; this grid fixes point 1 , with which the central lobes are set, as well as the tangency point 4 . The circumference with its centre in 5 is designed with the same circumference with which the central lobe is drawn.

When carrying out the geometric reconstruction of ribs in figure $4 \mathrm{~B}$, it can be observed that the diagonal rib is a circumference elevated $15 \mathrm{~cm}$ at the springing level. Using the real measures of the vault, its elevation has been reconstructed and it is possible to see that the height of the boss of tierceron 2 and the formeret 3 is located on the path of the diagonal rib (points 2 and 3). The same thing happens with the secondary bosses $A, B$ and $C$. The result is a vault whose ridges are nearly horizontal, barely a slight inclination from the central keystone 1 to the keystones of formerets 3 . Hence, the formerets and tiercerons are pointed arches formed with segments of the semicircumference of the diagonal rib. Figure 5 shows a three-dimensional reconstruction of this vault showing the shape obtained as a result of designing the vault according to these principles.

\section{4. - Vaults with tilted arches}

At the northwest angle of the cloister of Segovia cathedral is located a vault built by the architect Juan Guas, which stands outs for the originality and singularity of its composition (figure 6). It is quite singular the fact that there are only two planes of symmetry instead of four; the symmetry only exists in the vertical plans containing the diagonal arches. In addition, there is no central keystone, since the ogival arches compose a central rhombus, in which have been carved as folds of the filling shell the geometrical lines where the ribs should continue. This singular design can be observed in some medieval German sources, such as the collection of drawings "Wiener Sammlungen" or in the "Frankfurt Notebook" (Böker, 2005. Bucher, 1979).

However, once again, the versatility of the system enables to easily obtain the layout of this vault (figure 7). Although physically they are not complete, the diagonal ribs form a semicircle which determines the height of the central point of the vault. After drawing the arches, the architect defines the form of the vault, which is determined by its two cross sections. Both lines, the longitudinal and the transverse ridge lines define the 
"fall" of the vaulted surface toward the formerets and transverse arches and, also, determine the height of the boss located above them.

With these premises, the diagonal ribs, tiercerons and formerets should be different, each one with its particular curvature. However, a more detailed examination points out singular resources so that all the ribs can be drawn with only one curvature (figure 7). First of all, the radius of the diagonal arch is determined by the semi-diagonal of the square (since this arch is a semi circumference), and, likewise, the height of the central keystone 1 . Then, the tierceron (point 3 ) is located at the height fixed by the ridge line; the same diagonal rib is used to design this arch, just by rotating it around the starting point until it reaches height 3 . Obviously this rib will have its centre below the impost's line and does not start tangent to the vertical line at the impost level; there is a small dodge at the start which is almost not noticeable. The procedure for the formeret is the same; again, from its springing the diagonal rib is rotated until it reaches height 4; the rib, at the impost level, starts again inclined, and its centre is located below the impost's line.

Therefore, it could be said that this method to standardize curvatures is opposite to the one described previously. In the first case, the shape of the vault was a consequence of using the same diagonal arch for the rest of the arches; the result was a flat ridge line vault that has no possible variation. With the method just described, the form of the vault is previously determined; that means that the vault will adopt any desired form; subsequently, the heights of its main bosses will be obtained when drawing its ridge lines; it is necessary just to rotate the diagonal rib to reach the height of all the bosses.

At the Escuela de Arquitectura de Madrid, the mentioned hypotheses were verified through the construction of a model of Juan Guas' vault (figure 8). The scale 1:3 was chosen in order to have the biggest model that could be built inside the workshop's room. This experience is a confirmation of the feasibility of the construction method. The results of these skilful resources are obvious: all the ribs have the same curvature, or, in other words, the whole vault is built with only one arch, and, therefore, all the voussoirs are equal. The search for the standardization and systematization is clearly proved in this case, even though the geometric design is really sophisticated and singular.

\section{5. - Vaults with oval arches}

A new kind of vaults developed during the late Spanish Middle Ages is the oval starshape ribbed vaults. These are vaults in which the diagonal arches, instead of semi circumferences, are ovals; arches with three centres. They could be described as depressed vaults, although sometimes, at their springing level, they can be elevated to reach a similar height in the central keystone to that of a regular vault. In this type of vault only the diagonal and the transverse ribs are complete ovals; the curvatures of the other ribs (tiercerons and formerets), are usually a portion of the oval arch described by the diagonal rib. Therefore, following symmetry, these ribs become pointed arches with four centres: Tudor arches. The use of oval ribs as combination of two circumferences has been already studied (Willis, 1910). These vaults have some important advantages. First of all, since they are depressed vaults, the general height of the building is limited and so is its cost. Secondly, they are vaults with a flatter surface at their highest point, which makes possible more complex designs, such as concentric circles that are difficult to carry out on a more curved surface. In addition, the use of oval ribs allows the standardization to a great number of ribs. As figure 9 shows, once the diagonal rib's oval with its centres on $\mathrm{C} 1$ and $\mathrm{C}^{\prime}$ ' is drawn, the tierceron 2 can be drawn also with the same curvature: the lower part of the oval, with 
its centre in $\mathrm{C} 1$, and the upper one, sliding the upper curvature of the oval from the tangency point T to T'. This clever use of the two oval fragments enables the rest of the ribs that form the vault to be solved with the two curves with which the diagonal oval is composed.

This case is illustrated by a vault carried out by one of the most creative architects of Spanish late gothic period: Juan de Álava. This vault was built in the cloister of San Esteban monastery, in Salamanca, around 1533. It seems to be a quite simple vault, but its design reveals unsuspected features (figure 10). It is in fact a square vault with five keystones. As shown in figure $11 \mathrm{~A}$, the tiercerons $(0-2)$ are placed in the middle of the angle between the diagonal and transverse ribs (or between the diagonal and the formeret ribs). The way to place this arches begins with a circumscribed circle to the main square. A straight line is drawn from the corner 0 to the point 1 (where the line that goes from the centre of the vault rightwards crosses the circumference). This line also meets at point 2 (where the tierceron's boss is located) the line that goes from the centre of the vault until the point 4 (middle point of the vault's side). The vault has four subsidiary ribs following circumference quarters whose location seems to be determined by the alignment A-B-C. These are open subsidiary ribs, used to connect with that of the adjoining vault and to create a linking of ribs.

When analyzing the arches (figure 11B), it can be seen that the diagonal arch's keystone is below the theoretical semi-circular arch; this arch is, therefore, a depressed arch which has to be traced with three centres. The oval 1, with centres C1 and C1', which seems to adjust accurately to the real rib, was drawn with the measurements that could be taken in situ.

In relationship with the tiercerons, they must reach the height determined by the horizontal ridge line of this vault. It is obvious that the tierceron and the formeret could be pointed arches different from each other, but it is quite easier to build them with the same diagonal rib since that allows setting all the ribs of the whole vault with the same curvature. To carry out this operation, it is necessary just to roll $15^{\circ}$ the upper part of rib 1 over its lower part; this operation moves the keystone from point 1 to position 2, and also the tangency point of the oval moves from t1 to t2. The keystone of formeret 3 is located in the same way, now making the upper part of oval 4 roll over the lower part. Three ribs are obtained following this way; they are different but they have the same upper and lower curvatures. This method simplifies very much the carving of voussoirs. Also, since the vault is depressed, it has a flattened ridge profile which allows placing the central circular rib. Over a flat surface, it is possible to build this circumference avoiding many fragmentations. The same thing happens with the corner's secondary rib. Thanks to the fact that the main ribs of the vault have the same lower curvature, it can describe a continuous and horizontal circumference. Finally, it is remarkable that the vault covers its filling cells in a French way, that is, as a groined vault. The threedimensional image (Fig. 12) allows a clearer display of the resulting vault.

\section{6. - Vaults with inclined oval arches}

To illustrate the geometric principles of this new way to project a vault, it will be taken into consideration the vault of the upper choir of San Esteban convent in Salamanca (figure 13), also built by architect Juan de Álava around 1520. The points obtained through the measurement with total station are shown in figure 14. It is a strongly depressed vault, a flat vault achieved thanks to the use of oval arches of little elevation. Such ovals appear in some medieval drawings showing a geometrical construction that consists on dividing the main axis into several parts (Böker, 2005). 
This vault has a rectangular plan, whose approximate dimensions are $15 \times 7.5$ meters (figure 15). The ridge lines of the vault are the longitudinal and transverse curvatures. For the longitudinal ridge (in the direction of the nave's axis) Juan de Álava determines a straight and horizontal line that means that the height of the central keystone must be the same as that of the transverse rib; on the contrary, in the transverse direction, he fixes a slightly curved ridge line with a slope towards the formeret's keystone. These two lines are essential since they define with precision the shape of the vault and, in addition, they fix the height of the secondary bosses.

To determine the curvature of the tiercerons, the architect seems to have used the strategy summarized in the sketch in figure 16. First of all, the lower part of the oval, which is not strictly an arch, coincides exactly with the springing of the vault and it is built with horizontal courses. These horizontal courses reach the height of the point of tangency between the upper and lower curvatures of the diagonal oval. This oval has been traced with the height of the central keystone (point 1) that the architect deemed appropriate. Secondly, the architect determines that all the tiercerons have to be oval arches with identical curvatures to that of the diagonal rib. Next, two conditions that will simplify the construction of the vault are set. First, the lower part of the tiercerons' oval is made to coincide with that of the diagonal arch, and then the height of the springing which fixed the diagonal arch, $\mathrm{H}$, is determined so as to be identical for all the ribs (see again figure 16). With these conditions, the tiercerons are traced easily, making the upper part of the diagonal arch rotate around the point $\mathrm{H}$ until it coincides, on the other end, with the height of each one of the bosses. The vault has been built with only one arch: the upper part of the diagonal rib's oval.

At the Escuela de Arquitectura (Madrid), there was a chance to test the hypotheses exposed in the previous paragraphs by means of the construction of a model of this vault; the experiment allowed to confirm of the previous considerations. To carry out the vault, in first place, its real size layouts (plan and elevation) were drawn. Following the use of the medieval stonemasonry workshops (Rabasa, 2000), the information which allowed to undertake the carving of each one of the pieces that form the vault was extracted from these drawings (figure 17). Once the carving process was finished, the setting up of the vault started by placing the pieces over wooden centrings (figure 18). Since all the centrings have the same curvature, the process was quite simplified. The final result is a reduced model of the vault which confirms the hypotheses proposed (figure 19).

\section{3. - CONCLUSIONS}

Late Gothic architecture, built along the $15^{\text {th }}$ and $16^{\text {th }}$ centuries, has often been unfairly considered as a style that goes on beyond its limits over the Renaissance. However, the beauty, the creativity and the technological developments which underlie the vaults of that period make us think that it is precisely at that moment when this style reaches its highlight point in Europe.

From a constructive point of view, the technological evolution is marked by a tendency towards the search for standardization and systematization. While the designs of the vaults got more complex and elaborated features, technological resources which allowed an easier construction were developed. The systematization of the curvatures of the ribs implies clear benefits. In a direct way, the execution of the voussoirs is somehow simplified, since all the pieces are equal. However, the most significant advantages are related to the organization of the works. On one hand, it reduces the necessities of numbering and classification for the storage and placing of the voussoirs. On the other hand it makes easier the transmission of executing orders from the 
masters to the stonemasons. The design of the architect had to be translated into instructions for the workers and, even though some of the methods exposed broke the geometric integrity of the ribs, the equating of curvatures implied a great advantage for this transmission. The conceptual geometry of the project was adapted to the practical reality of the works, since the differences could not be appreciated at first glance.

The more complex design entails a greater number of ribs. This feature also allows an easier construction of web spandrels, since no wood centrings are needed. Moreover, it could be pointed out that a bigger amount of ribs might collaborate to provide a better equilibrium of the vault.

The construction of vaults' real models (Martin and Palacios, 2009), is a powerful tool that has two main purposes. First of all, as a method of analysis it allows to confirm the geometrical and technological hypothesis with which the vault could have been built. Secondly, as a pedagogical tool through which to transmit the medieval technology in the most efficient and creative way to students of architecture. In this way, pupils can reach not only a theoretical knowledge, but also a rewarding experience based on the "medieval-way" praxis (figure 20). 


\section{4.- BIBLIOGRAPHY}

BÖKER, HANS JOSEF. Architektur der Gotik: Bestandskatalog der weltgrößten Sammlung an gotischen Baurissen (Legat Franz Jäger). Pustet. München. 2005.

BUCHER, FRANÇOIS. Architector. The lodge books and sketch books of medieval architects. New York. 1979.

BUCHER, FRANÇOIS. The Dresden sketch-book of vault projection. Proceedings of the 22nd congress of art history. Budapest. 1972.

FRANKL, PAUL. Gothic Architecture. 1962. Penguin books. Reedición: Manuales Arte Cátedra. Madrid. 2002.

GARCÍA, SIMÓN. Compendio de arquitectura y simetría de los templos Colegio Oficial de Arquitectos de Valladolid. Valladolid. 1991

GÓMEZ MARTíNEZ, JAVIER. El gótico español en la Edad Moderna: bóvedas de crucería. Ed. Universidad de Valladolid. Valladolid. 1998.

LAMBERT, ELIE. El arte gótico en España en los siglos XII y XIII. Editorial Cátedra. Madrid. Reprint 1920.

MARTÍN, RAFAEL Y PALACIOS, JOSÉ CARLOS. La construcción de una bóveda de crucería en la Escuela Técnica Superior de Arquitectura de Madrid. Informes de la Construcción. Vol. 61. Consejo Superior de Investigaciones Científicas. Madrid, 2009.

MERINO DE CÁCERES, JOSÉ MIGUEL. El claustro de la catedral de Segovia. Instituto Diego de Colmenares. Diputación Provincial de Segovia. Segovia. 1996.

MÜLLER, WERNER. Grundlagen gotischer bautechnik: ars sine scientia nihil est. Deutscher Kunstverlag. München. 1990.

PALACIOS GONZALO, JOSÉ CARLOS. Trazas y Cortes de Cantería en el Renacimiento Español. Munilla-Lería. Madrid. 2003

PALACIOS GONZALO, JOSÉ CARLOS. La cantería medieval, la construcción de la bóveda gótica española. Munilla-Lería. Madrid. 2009

RABASA DÍAZ, ENRIQUE. Forma y construcción en piedra. De la cantería medieval a la estereotomía del siglo XIX. Akal. Madrid. 2000

VIOLLET-LE-DUC, EMMANUEL. Dictionnaire raisonné de l'architecture française du XI au XVI siècle, 10 vols. 1854-1868

VIOLLET-LE-DUC, EMMANUEL. Histoire d'un hôtel de ville et d'une cathédrale. Pierre Mardaga. Brussels. 1978

WILLIS, ROBERT. On the constructions of the Vaults of the Middle Ages. Transactions of the RIBA, Longman, Brown, Green and Longmans. London. 1842, reprint, 1910. 


\section{5. - FIGURES}

Fig. 1 Viollet-le-Duc's interpretation of Villard de Honnecourt's drawing (A) showing how all the arches of a vault can be drawn from a semi circumference. $B$, design of a five bosses vault from the semi circumference of the diagonal arch; the result is a vault with its ridge almost horizontal (Viollet-le-Duc, 1978).

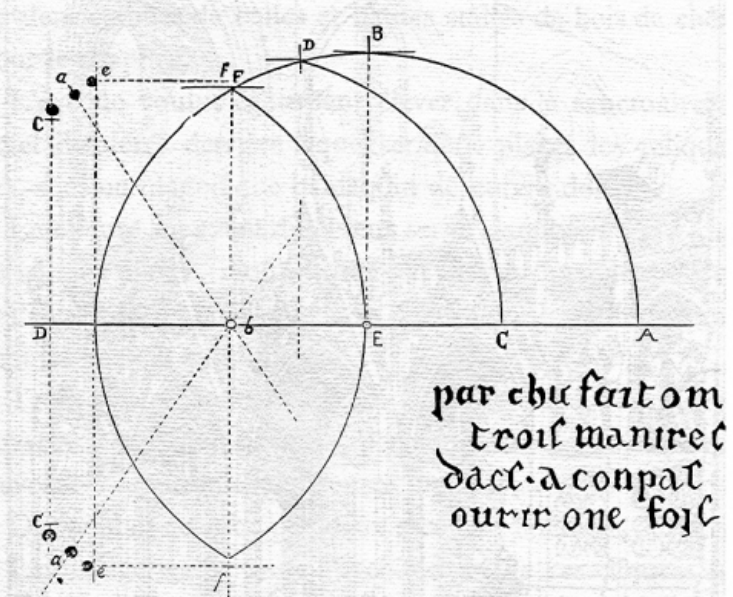

Ditart be tronecozt trovate bitlaume de cortenay

A

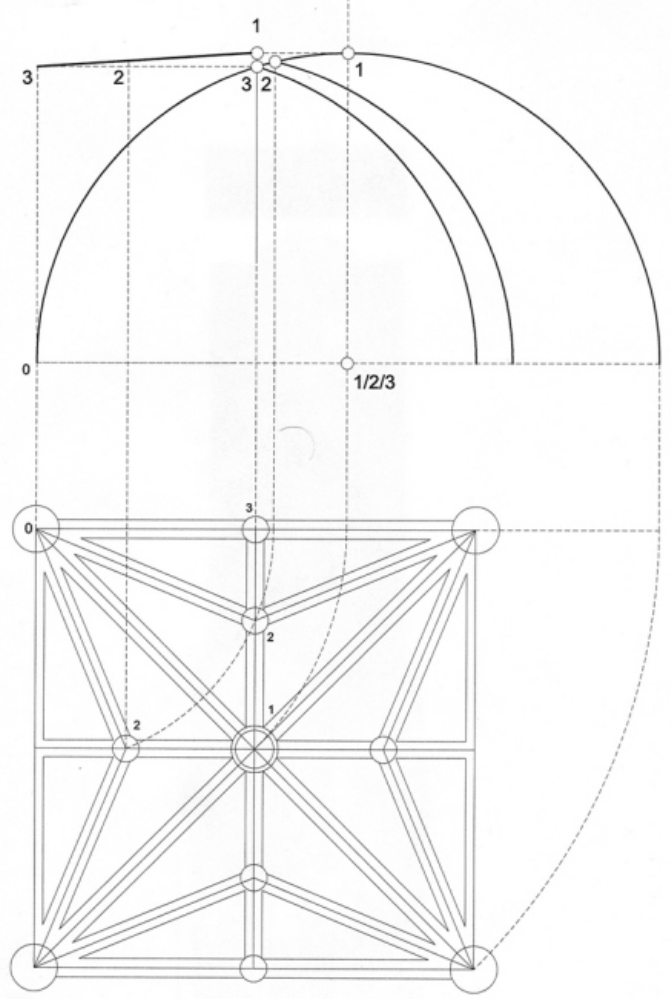

B 
Fig. 2

Sketches showing the four methods detected in the Spanish gothic vaults used to standardize the curvatures.
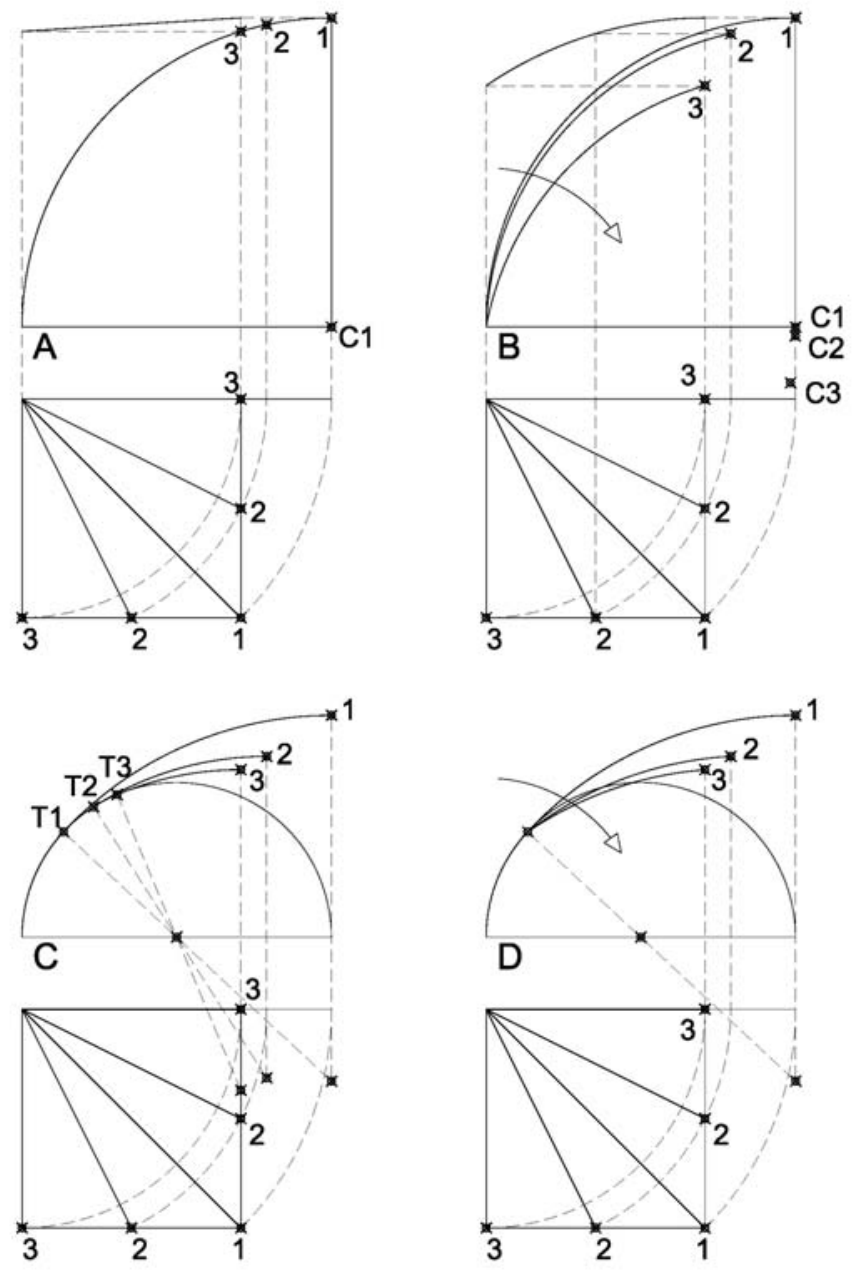

Fig. 3

Astorga

cathedral, vaults over the chapels of the transept aisle. Rodrigo Gil de Hontañón, between 1550 and 1570.

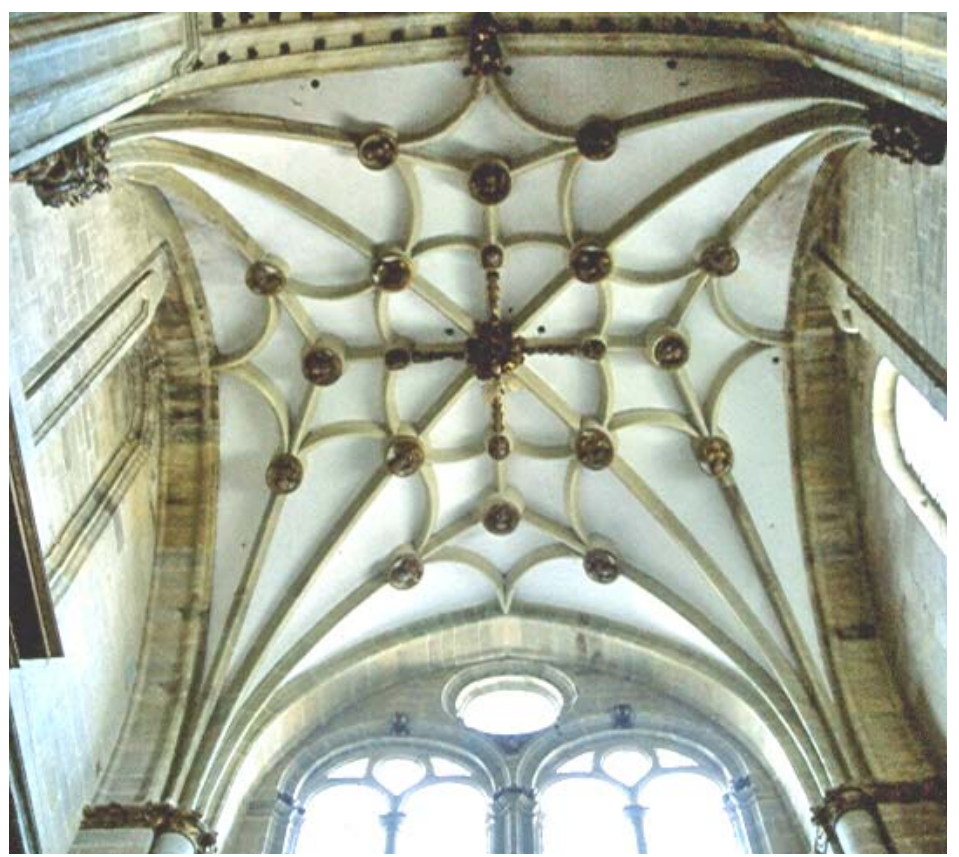


Fig. 4

Astorga cathedral, vaults over the chapels of the crossings; A, design of the plan and $B$, of the curvature of their arches.
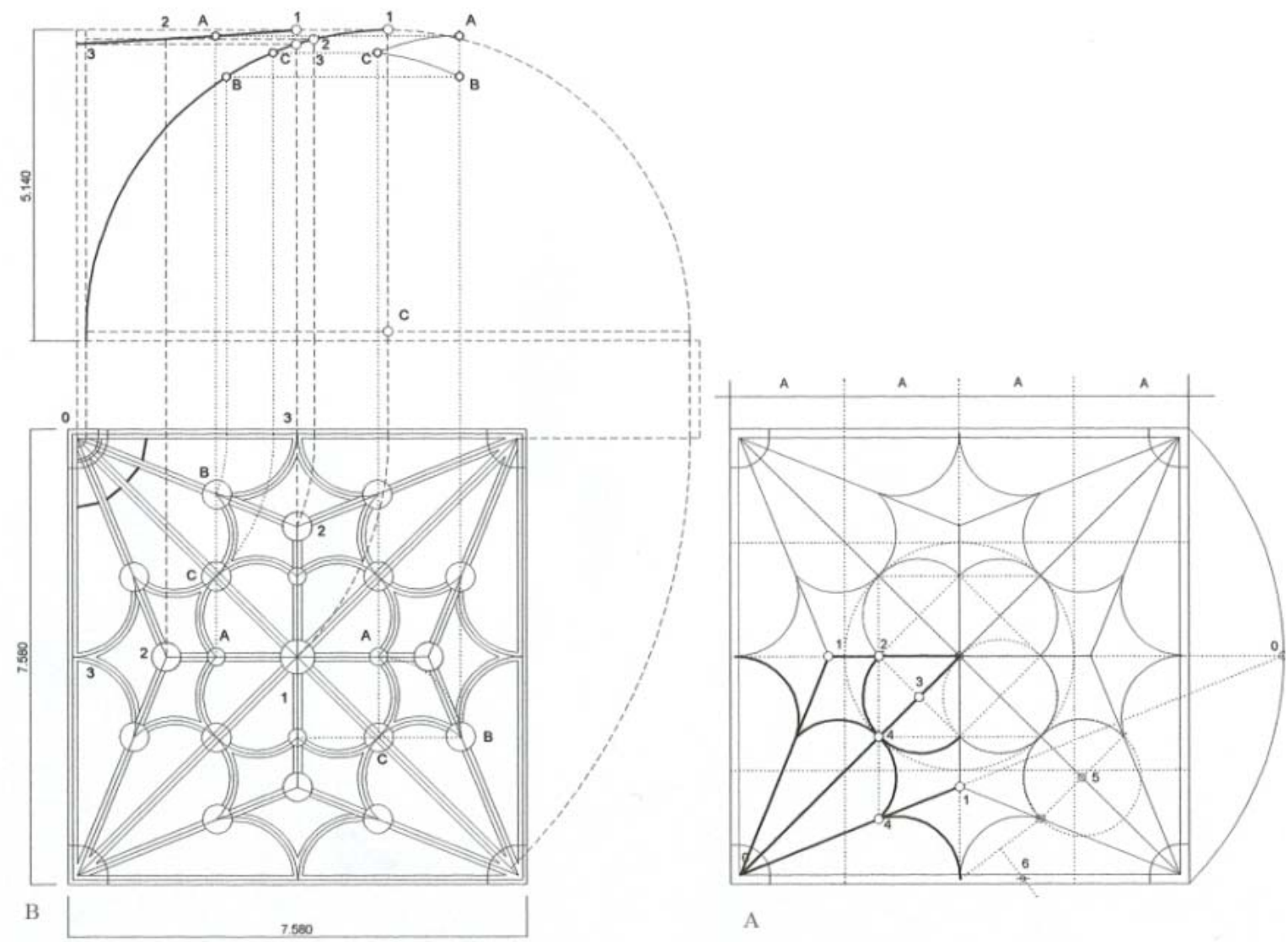

A

Fig. 5 Astorga cathedral, vaults over the chapels of the crossings. Model of the vault. Its semicircular diagonal, its flat ridge line, its ribs and bosses can be clearly seen

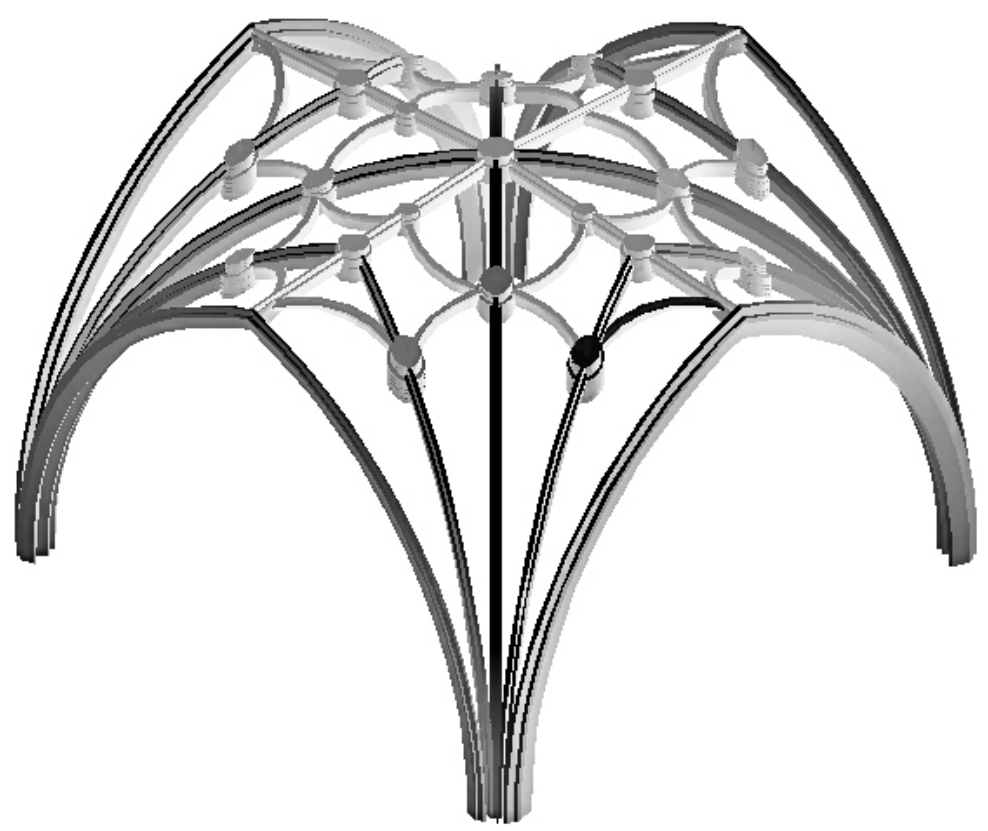


Fig. 6

Segovia cathedral, vault of the cloister. Asymmetrical crossing ribs in this vault built by Juan Guas.

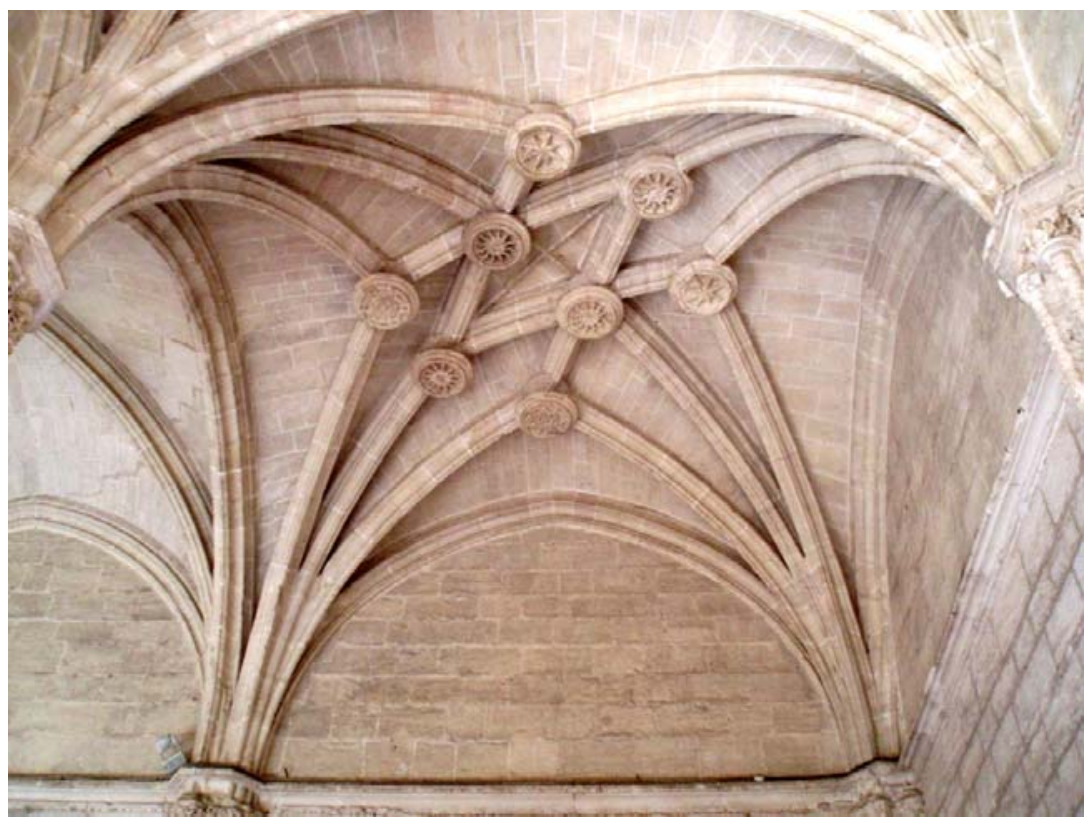

Fig. 7 Segovia cathedral, vault of the cloister. The vault is built with arches of the same curvature and inclined.

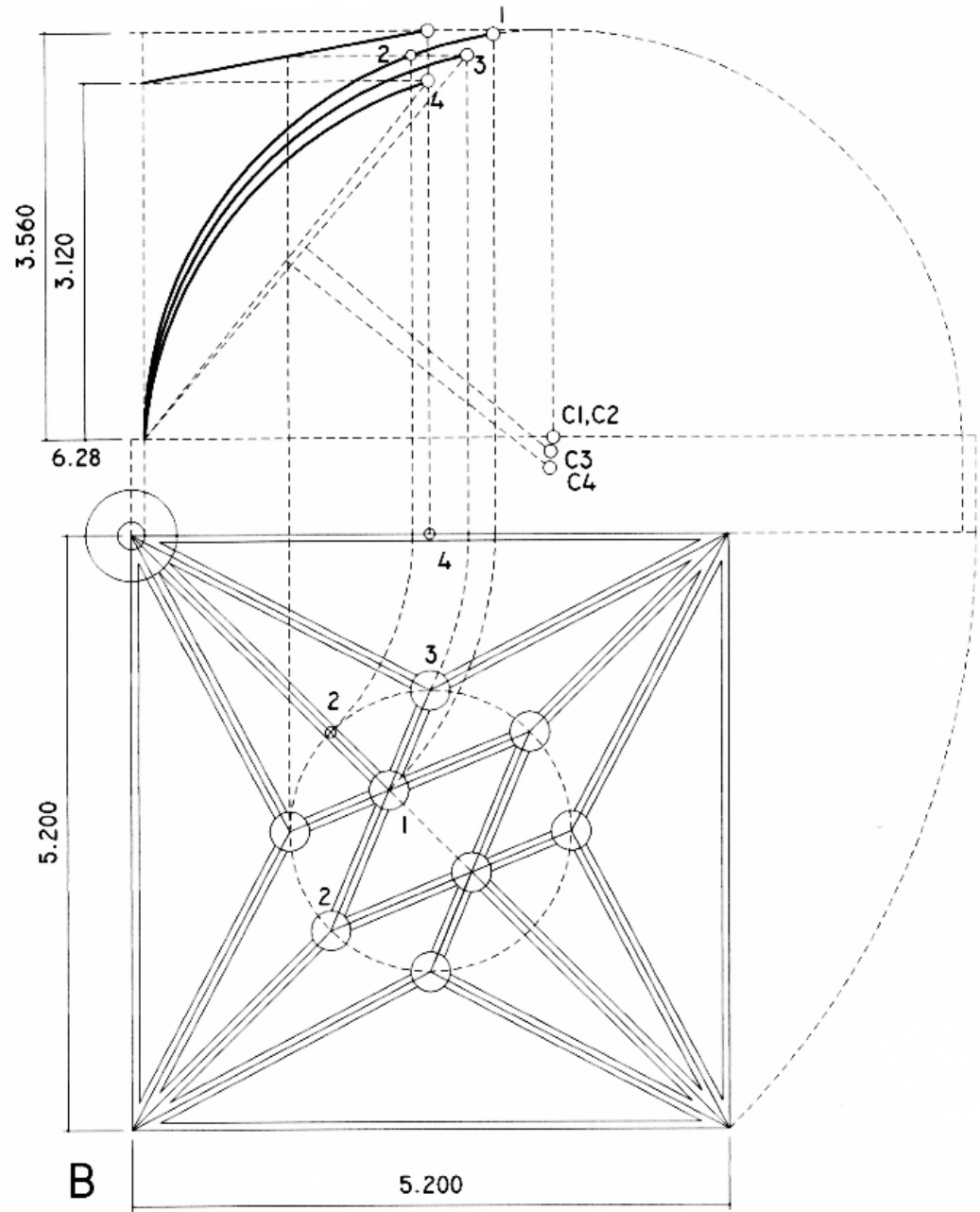


Fig. 8 Juan Guas' vault model built at the Escuela de Arquitectura de Madrid.

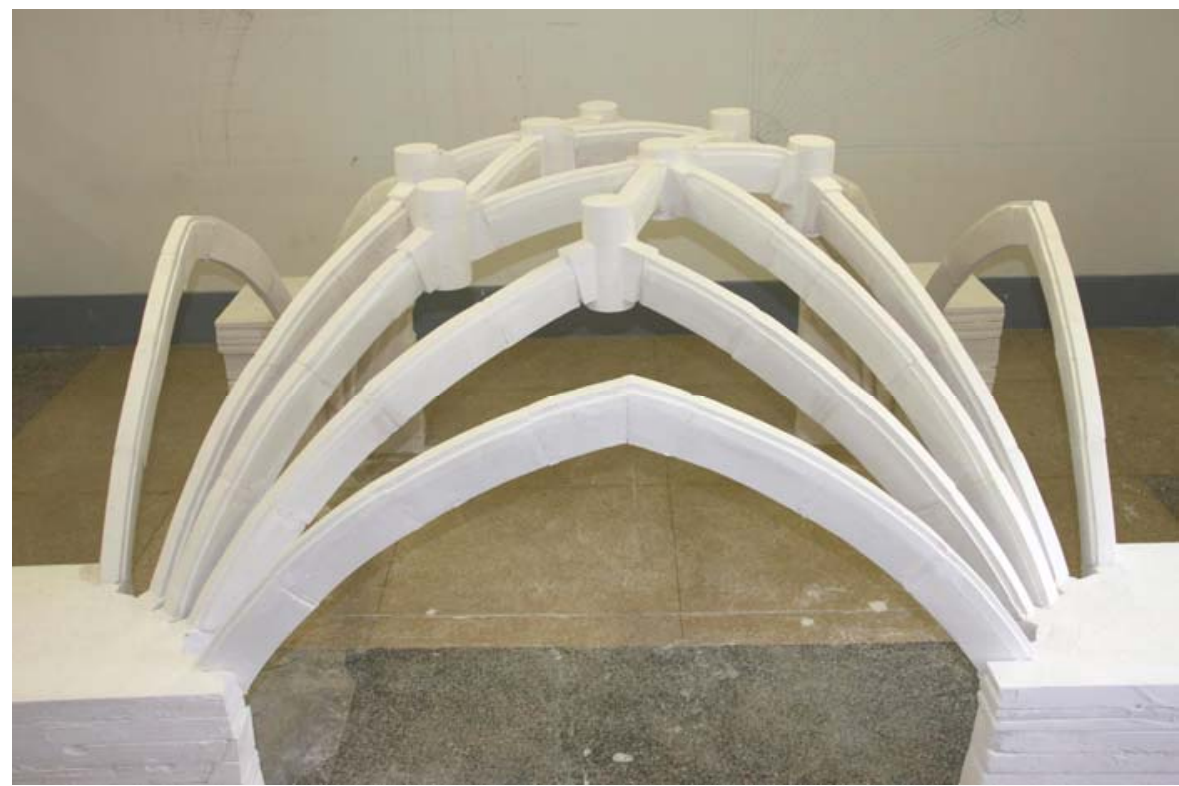

Fig. 9

The ribs of an oval vault can be standardized using always the same curvatures; in the figure the tiercerons and the diagonal arch are formed with the same arches.

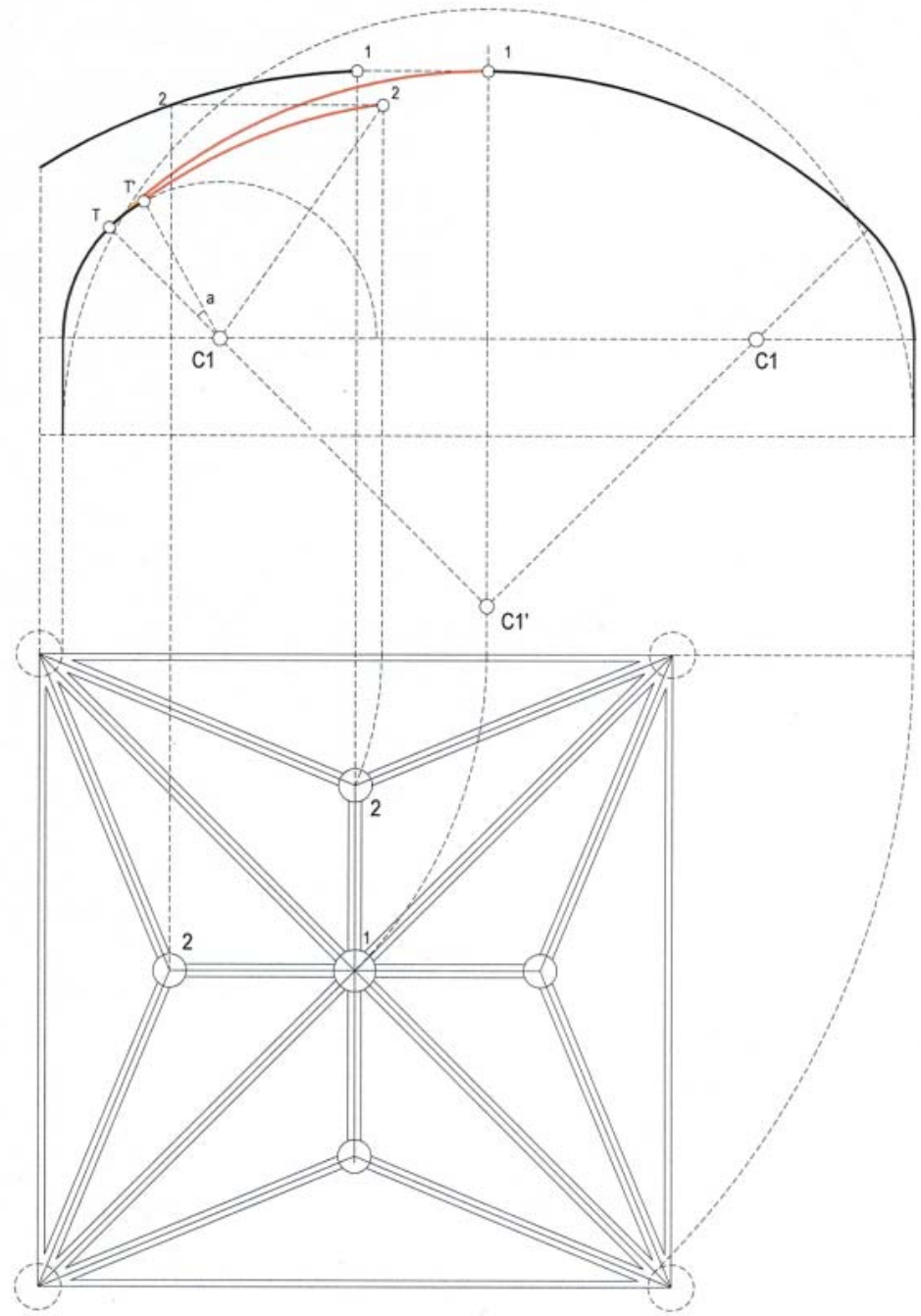


Fig. 10

San Esteban convent, Salamanca, cloister. Juan de Álava.

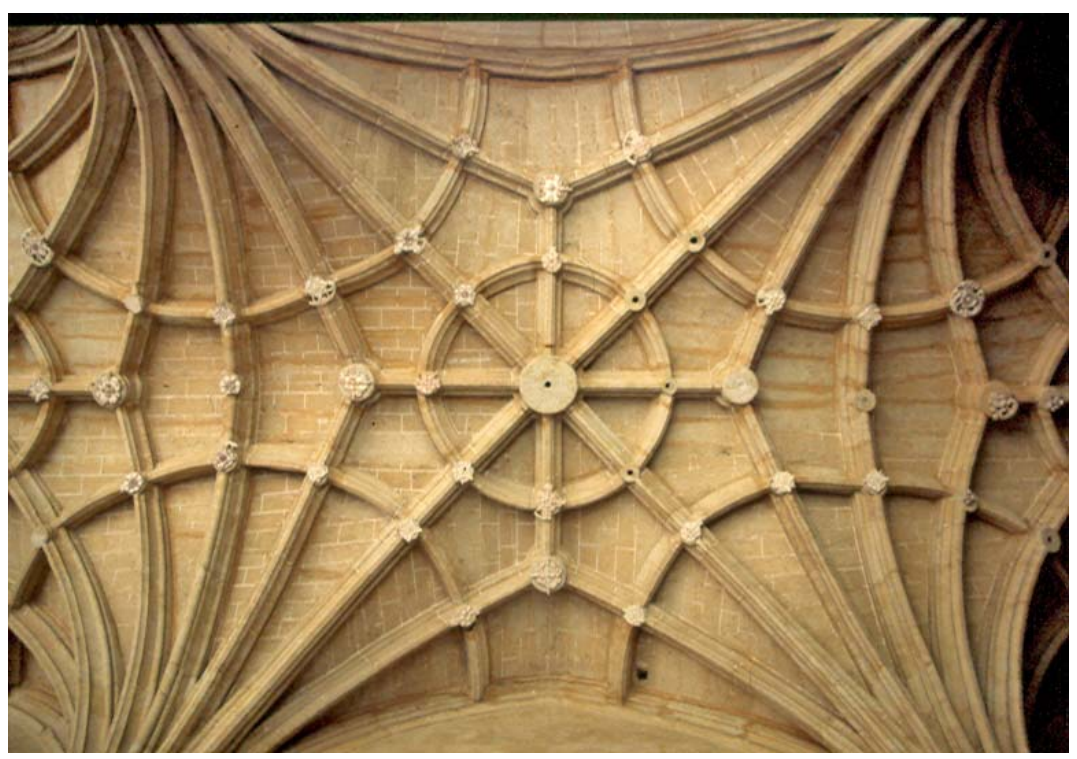

Fig. 11 San Esteban convent, Salamanca, cloister. Drawing plan, Fig. A, and curvature of its arches, Fig. B. See the diagonal oval arch and how the horizontal ridge line is obtained by sliding the upper part of the oval over the lower part. All the ribs are equal.

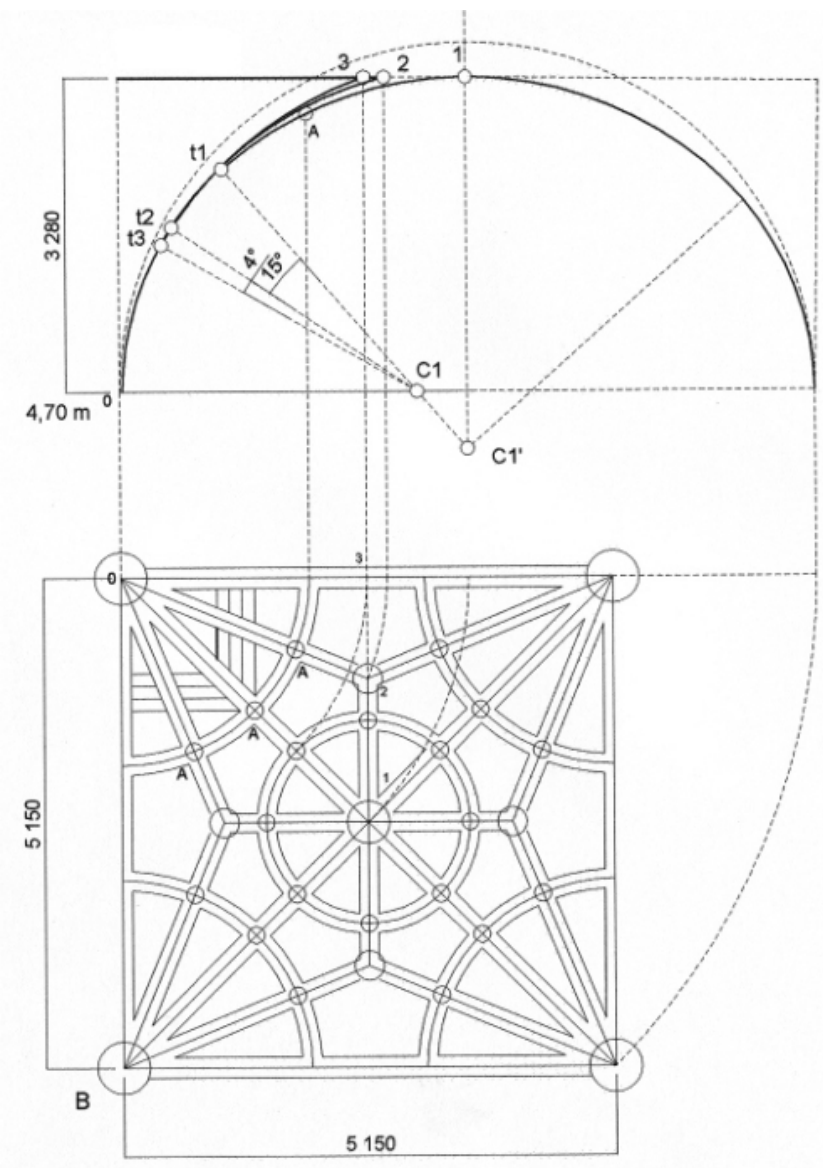


Fig. 12

San Esteban convent, Salamanca, cloister. Three-dimensional model of the vault.

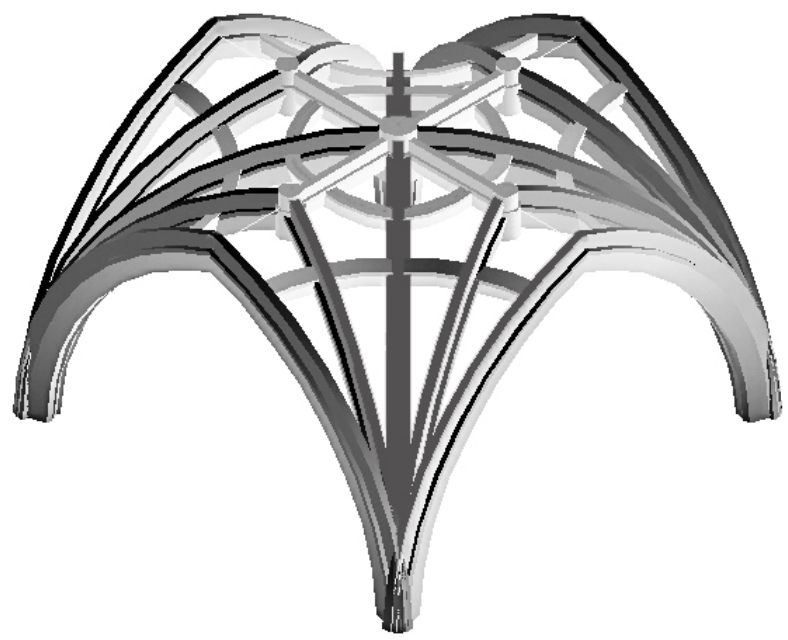

Fig. 13 Vault of the upper choir of the San Esteban convent in Salamanca built by Juan de Álava around 1520.

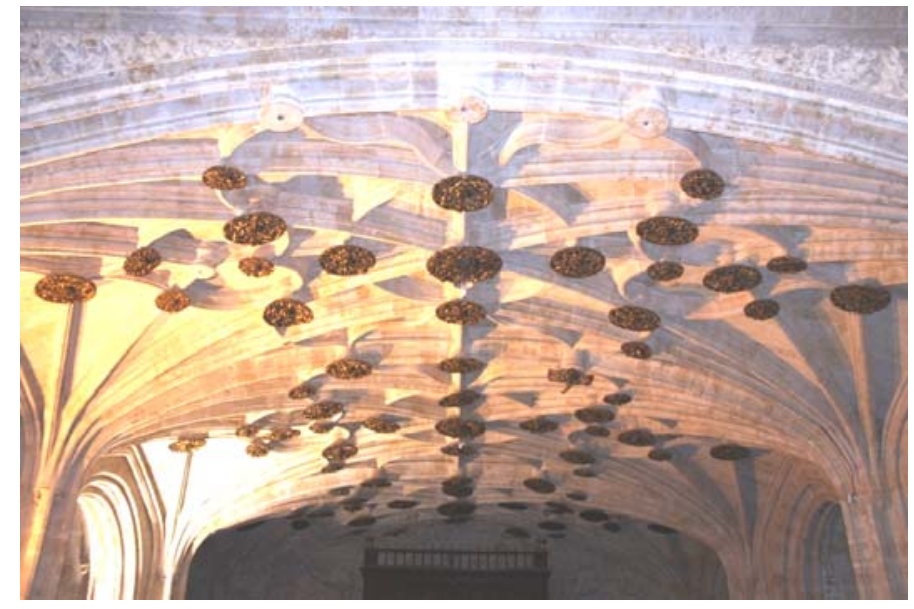

Fig. 14 Three-dimensional points-model obtained with topographical devices

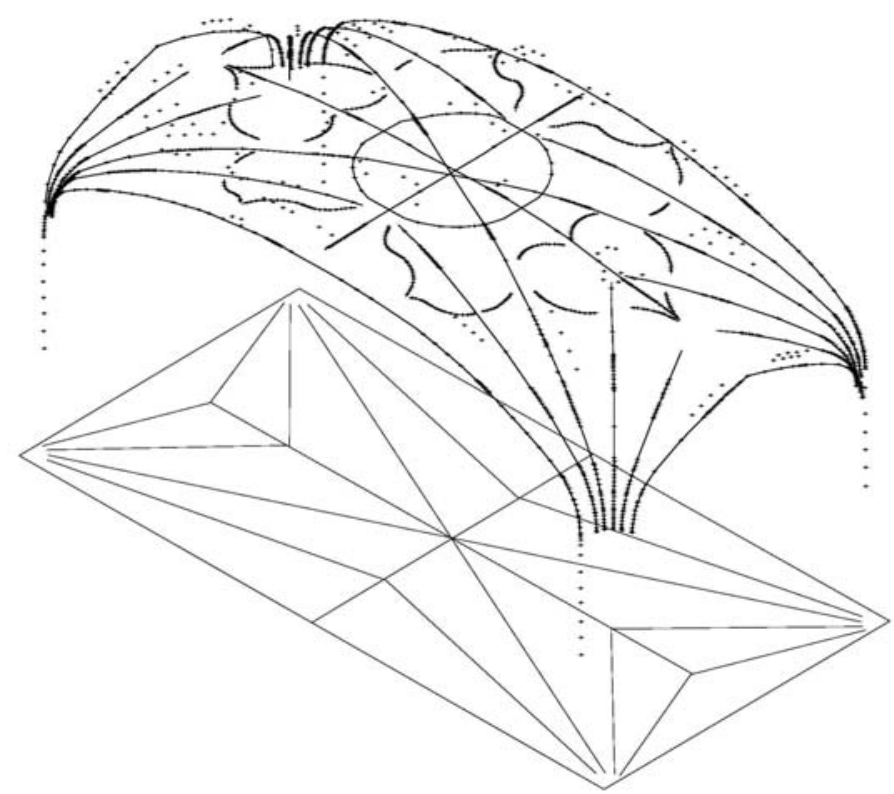


Fig. 15

Plan and sections of the vault showing its horizontal longitudinal section and its cross section curved and inclined over the formeret.

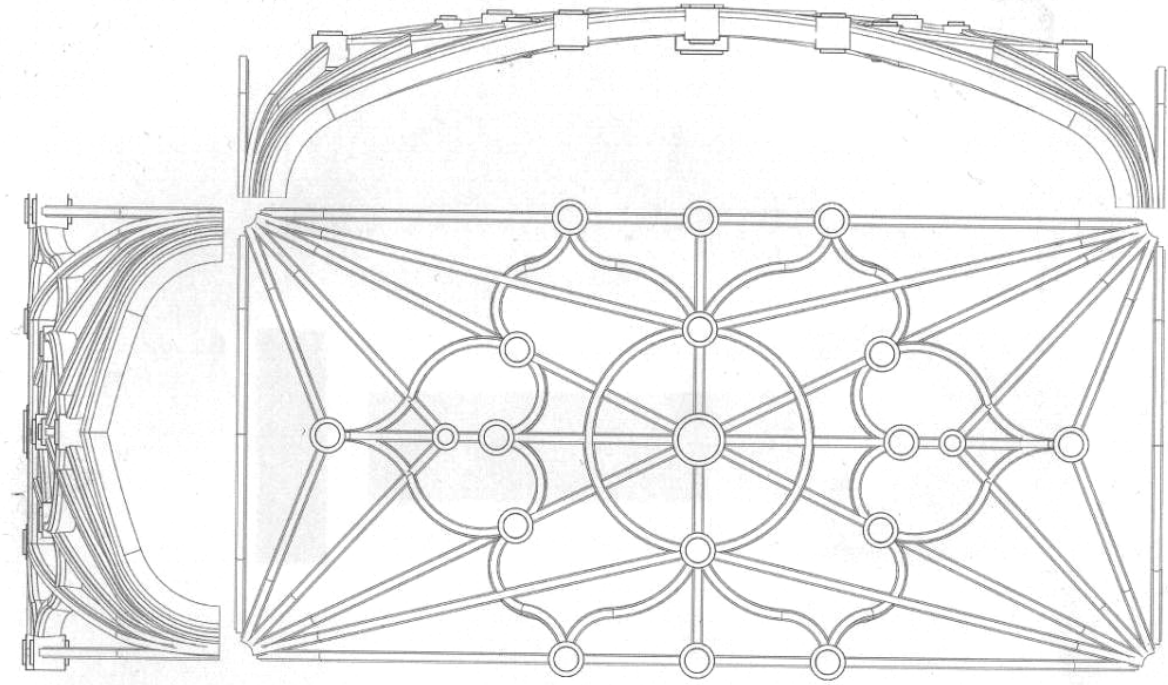

Fig. 16

Sketch in which the method followed by the architect to standardize the curvatures of the arches is shown. Every vault is traced with the upper part of the diagonal oval arch.

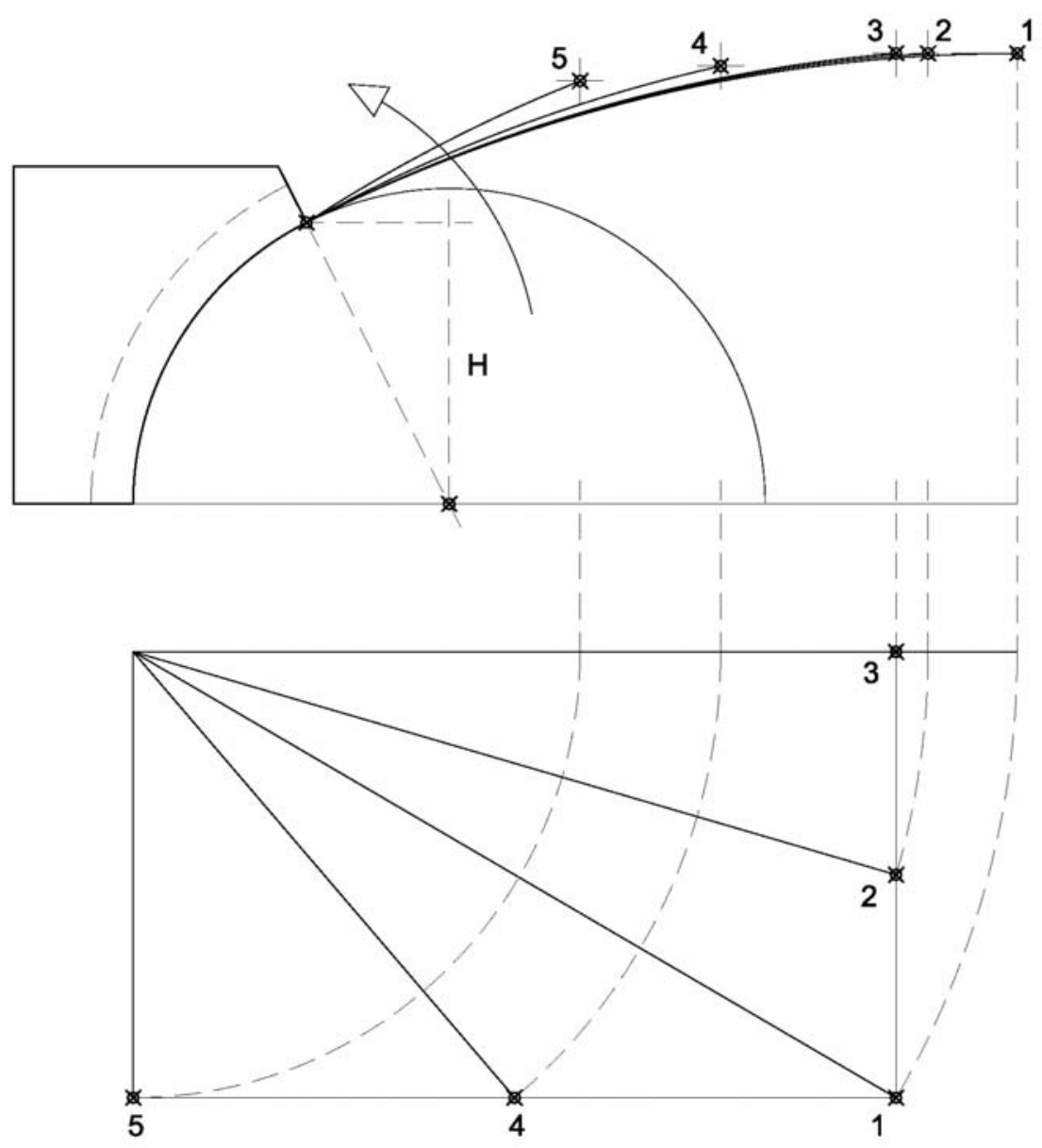


Fig. 17

School of Architecture of Madrid, real scale layouts used for the construction of a reduced model of the vault at scale 1:3.

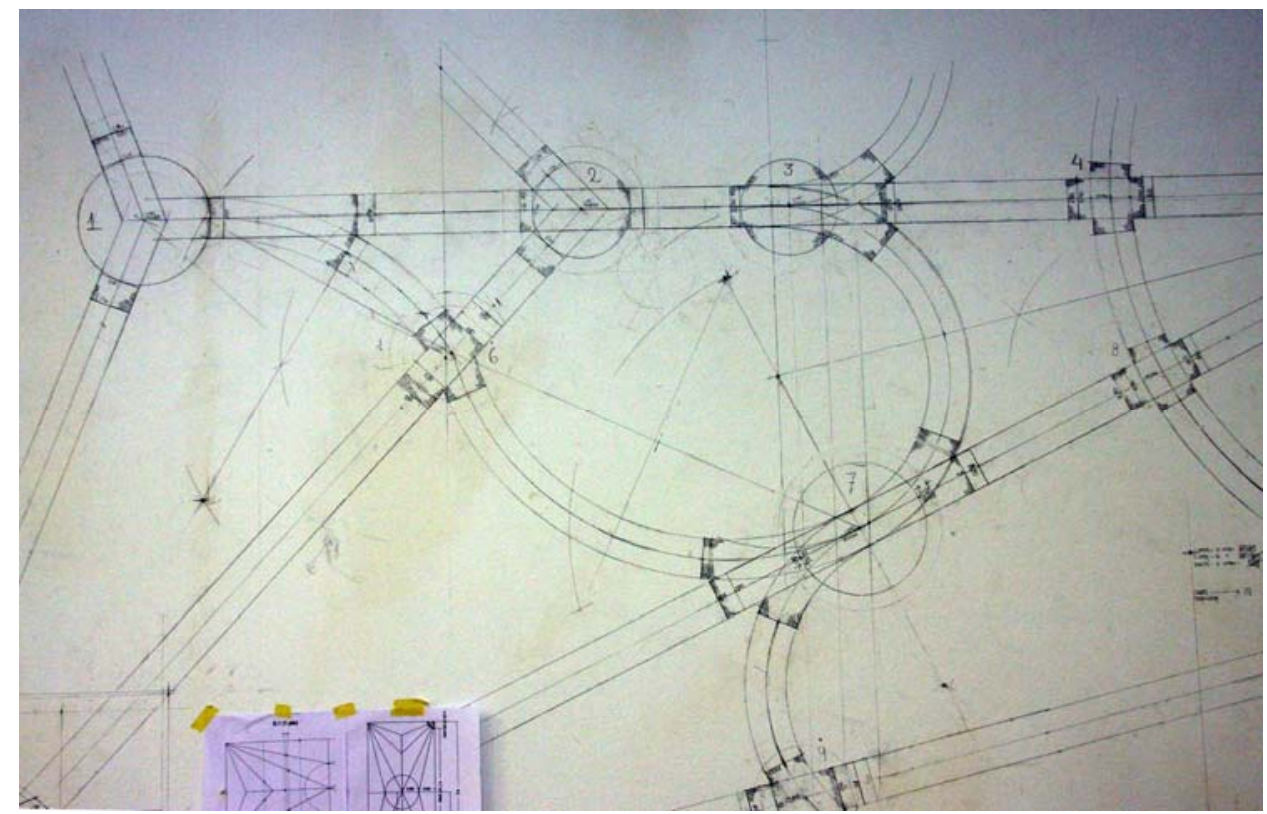

Fig. 18

Set-up; the different pieces composing the vault are placed on the centrings.

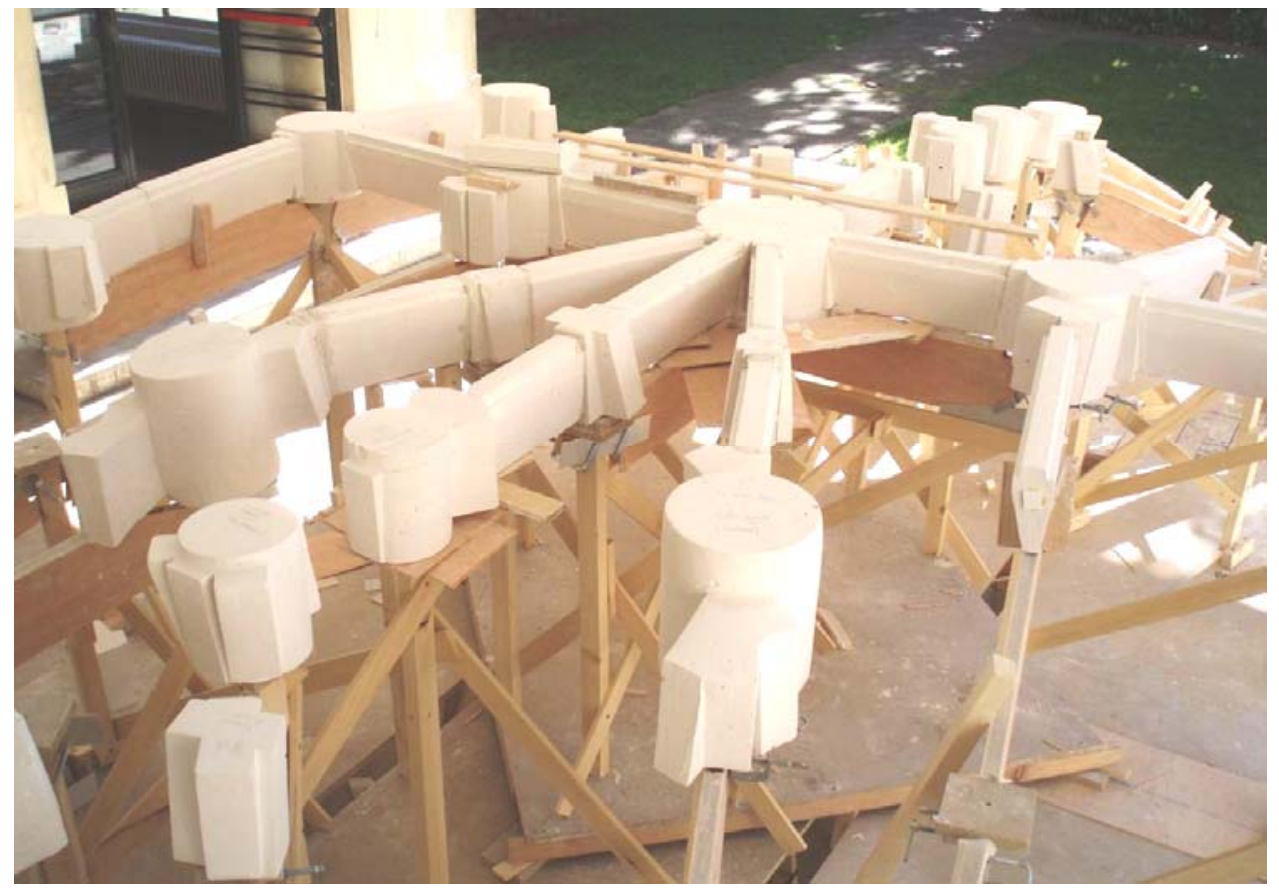


Fig. 19

Reproduction of Juan de Álava's vault, built with only one arch.

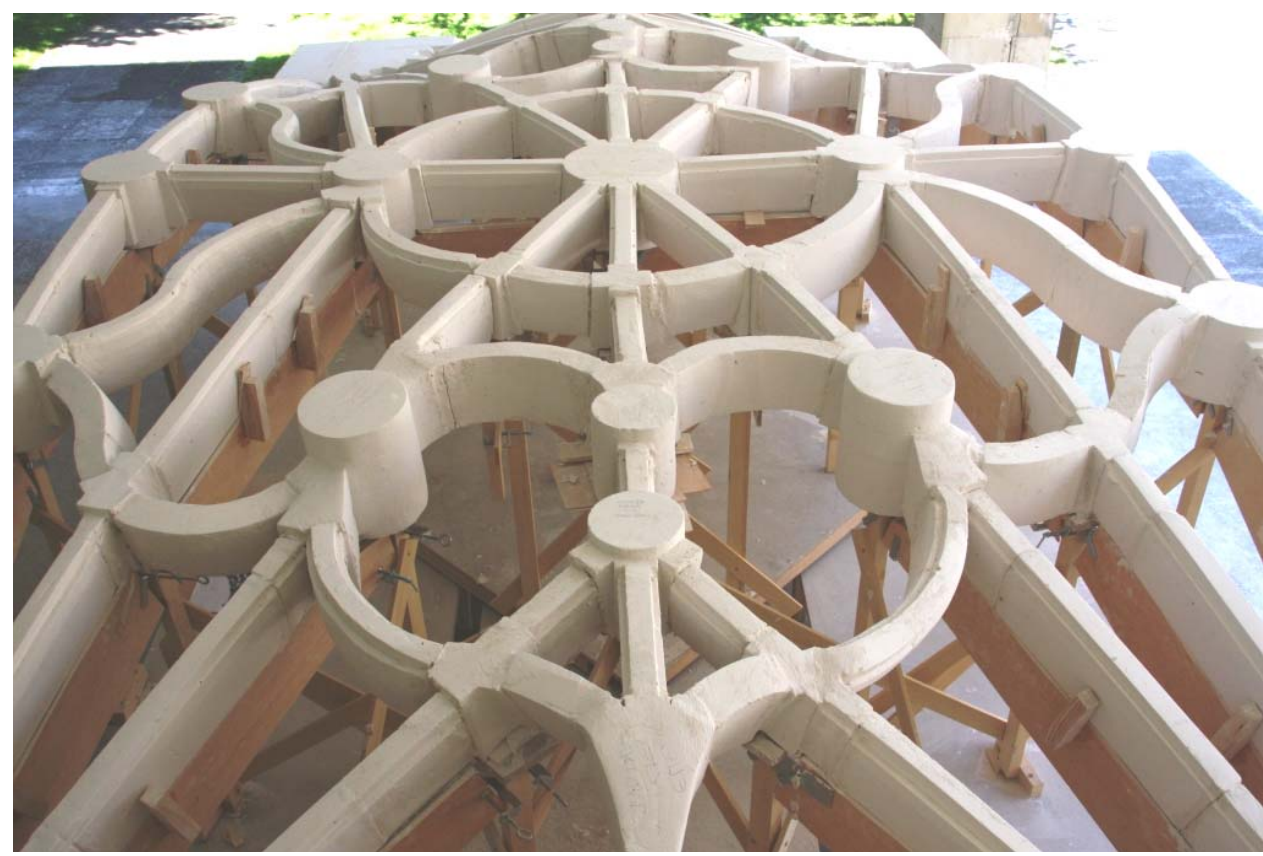

Fig. 20

Workshop at Escuela de Arquitectura de Madrid during the vault's construction.

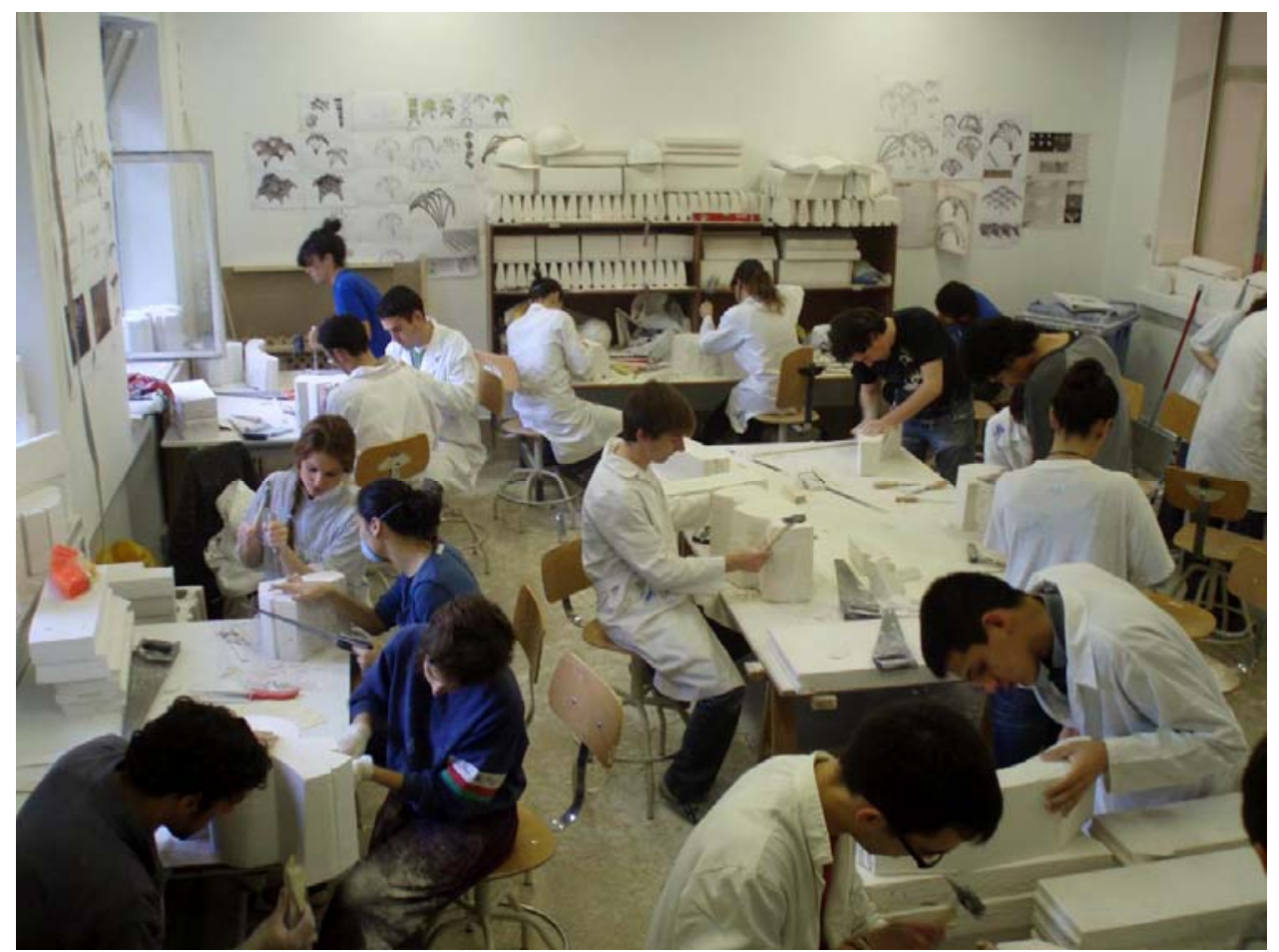

